\title{
Obtaining consent to a life-sustaining treatment for a patient with a major psychiatric illness
}

\author{
Albert Kadri MD, Jeff Blackmer MD, Muhieldean Ibrahim
}

1 53-year-old woman with a longstanding history of paranoid schizophrenia and advanced chronic kidney disease was brought to the emergency department by police and subsequently admitted involuntarily to the psychiatric service. Because of her mental illness, she had previously transferred power of attorney for medical decisions to her brother, who resided in another city.

The patient had a documented history of nonadherence to medical treatment. On this admission, her renal function had deteriorated substantially, with signs and symptoms compatible with uremia. Treatment with dialysis was discussed with the patient; however, she was deemed incapable of informed consent through a formal capacity assessment performed by the emergency physician and the psychiatrist. Her brother, the substitute decision-maker, subsequently gave consent to proceed with dialysis, stating that the patient had no previously documented wishes against life-sustaining therapy.

A tunnelled hemodialysis catheter was inserted through the patient's internal jugular vein into the right atrium, and dialysis was started. Several days later, the patient forcefully pulled out the catheter. Local pressure was applied until bleeding subsided. A second catheter was inserted to continue the dialysis therapy. Although the patient was agreeable and cooperative with dialysis initially, she consistently and adamantly objected to the treatment after two sessions. She forcefully pulled out the second catheter several days after its insertion. Hemostasis was achieved rapidly, and there was no substantial bleeding.

Joint meetings with the psychiatry and nephrology services ensued. The patient's anticipated clinical course and prognosis were discussed from both the psychiatric and medical perspectives, and the hospital ethics service was consulted. The patient's psychiatric condition was deemed not likely to improve despite pharmacotherapy. Electroconvulsive therapy was considered, but the psychiatry service felt that it would not be of benefit. During the discussions, it was clearly outlined that the patient would likely experience progressive uremic symptoms and eventually die of renal failure without dialysis therapy.

Because of the substantial risk of exsanguination and death if the patient continued to forcefully remove her dialysis catheter or dislodged other blood lines, the medical staff was apprehensive about resuming the dialysis therapy. The patient's brother agreed that her verbalizations and actions constituted evidence that she was unwilling to proceed with the dialysis.

After comprehensive multispecialty meetings that involved the patient's brother, the brother withdrew consent for dialysis because he thought that the associated risks outweighed the benefits. Supportive care and medical therapy were continued.

\section{Discussion}

This case illustrates the complexities encountered when a patient's major psychiatric illness is the main factor in the decision not to offer, or to withdraw, dialysis therapy. Although some of the details in our case are specific to the province of Ontario, the concerns are relevant to physicians across Canada and those in other countries.

The Ontario Health Care Consent Act $^{1}$ provides health care practitioners in the province with the legal parameters surrounding what constitutes valid consent to treatment from either the
Competing interests: None declared.

This article has been peer reviewed.

\section{Correspondence to: \\ Albert Kadri, dr.kadri @ careforkidneys.org}

CMAJ 2014. DOI:10.1503 /cmaj.130714 
patient or the substitute decision-maker. It also provides for the possibility of reviewing a finding of incapacity, or appealing the decision of a substitute decision-maker, through the Ontario Consent and Capacity Board. The act sets out the rules for determining capacity in three key areas: treatment decisions, admission to care facilities and the provision of personal assistance services. It states that a person is capable in these areas if he or she "is able to understand the information that is relevant to making a decision about the treatment, admission or personal assistance service, as the case may be, and able to appreciate the reasonably foreseeable consequences of a decision or lack of decision." It thus sets forth a two-part test for capacity.

\section{Court decisions on consent to treatment}

Starson v. Swayze $e^{2}$ was the landmark decision on consent to treatment in Canada. On Dec. 24, 1998, Dr. Ian Gary Swayze declared Starson (a.k.a. Scott Jeffery Schutzman, a physicist with bipolar disorder) incapable of consenting to a proposed psychiatric treatment plan. Starson applied to the Ontario Consent and Capacity Board for a review of the decision.

The board sided with Swayze and ruled that Starson did not recognize that he was ill and needed treatment, was not able to understand the consequences of consent and lacked the capacity to make a decision about treatment. However, on June 6, 2003, the Supreme Court of Canada overturned this decision:

Capacity involves two criteria: first, a person must be able to understand the information that is relevant to making a treatment decision and second, a person must be able to appreciate the reasonably foreseeable consequences of the decision or lack of one. The legislative mandate of the Consent and Capacity Board is to adjudicate solely upon a patient's capacity and the Board's conception of the patient's best interests is irrelevant to that determination. ${ }^{2}$

Each province is responsible for legislation in this complex area. Only Ontario and Nova Scotia currently have formal consent and capacity boards. In the other provinces, patients have to pursue remedies through the legal system. The withdrawal of therapy was recently the subject of a ruling by the Supreme Court of Canada in Cuthbertson v. Rasouli. ${ }^{3}$ A full review of that decision is beyond the scope of this paper. The main implication of the ruling is that physicians in Ontario who do not agree with the wishes of a substitute decision-maker have to appeal to the Consent and Capacity Board, including in situations where physicians wish to stop treatment that they think is no longer medically indicated.
The Rasouli case applies only to Ontario, but it is widely anticipated that it will result in the formation of similar tribunals in other provinces, as patients and their family members grapple with complex and difficult end-of-life decisions.

\section{Provincial legislation on consent to treatment}

Although the exact details may vary by province, the issue of patient consent and proxy decisionmaking, as it pertains to legislation and regulations, is dealt with in a fairly consistent manner. The following excerpt from the Ontario legislation is a typical examples of the wording used:

With the exception of certain emergency situations, all treatment requires informed, capable, voluntary consent. If capable, the patient makes the decision. If the person is not capable, the decision is made on his or her behalf by a substitute decision-maker. ... Valid consent does not mean a signature on a piece of paper. For consent to be valid, it must be informed and be given voluntarily by a capable person. Consent may be oral or written; expressed or implied. ${ }^{4}$

\section{The role of the substitute decision-maker}

An appropriate substitute decision-maker has an obligation to follow the decision-making rules outlined in the Health Care Consent Act (Appendix 1, available at www.cmaj.ca/lookup/suppl /doi:10.1503/cmaj.130714/-/DC1). In doing so, he or she must first consider any prior expressed wishes (written or oral) of the patient that were made while the patient was deemed to be capable. In the absence of such wishes, the substitute decision-maker must act in the best interests of the incapable patient, taking into account the patient's values and beliefs, as well as the extent of benefit to the patient's well-being of any proposed treatment. ${ }^{5}$ Although "well-being" may be somewhat subjective and difficult to define, it is felt that someone designated as the substitute decision-maker will have sufficient knowledge of the patient's values and beliefs and will be able to help determine what is in his or her best interests. The substitute decision-maker must base the decision not on what he or she would want done but rather on what the patient would have wanted if capable and able to make the decision.

\section{Treating without formal consent}

A health care practitioner may treat without formal consent in certain emergency situations. These situations include temporary communication barriers to obtaining valid consent, a substitute decision-maker of an incapable patient not being immediately available, and a health care practitioner believing that a substitute decisionmaker has not followed the decision-making rules 
in the Health Care Consent Act. ${ }^{6}$ In the last example, a practitioner in Ontario may need to make an application to the province's Consent and Capacity Board to seek leave to override the wishes of the substitute decision-maker. Regardless of the jurisdiction, physicians and other health care professionals are always encouraged to seek legal and ethical opinions to better understand the situation and specific process to be followed.

\section{The case revisited}

Two ethical dilemmas challenged the health care team and the substitute decision-maker after the patient's initial dialysis plan was started. The first was the absence of voluntary acceptance of the treatment by the patient. It did not seem humane to force an invasive chronic therapy on a patient against her will or to use physical restraints to perform the procedure. That said, assent was not legally required for treatment, and from a legal standpoint, it would have been permissible to continue to provide the dialysis therapy.

A potentially difficult situation might have arisen had the substitute decision-maker not withdrawn his consent to the procedure and instead had insisted that the dialysis be continued and restraints used. The health care team would then have had to decide whether to challenge his decision and bring the case to the Ontario Consent and Capacity Board. Although the members of the team might have felt uneasy in providing the care, it is unclear whether the board would have sided with them in this type of situation. If it did, the individual practitioners would then have had to decide whether they could continue to provide care that is not in keeping with their personal moral convictions. There have been several legal cases in Canada where family members have requested aggressive treatment against the recommendations of the health care team. Examples include the Jin case in Calgary ${ }^{7}$ and the Golubchuk case in Winnipeg. ${ }^{8}$ These cases also illustrate the pan-Canadian relevance and importance of these issues.

The second ethical dilemma was the risk of doing immediate physical and emotional harm to the patient if the dialysis therapy were continued. The patient's actions of forcefully removing the dialysis catheters led the health care team and the substitute decision-maker to re-evaluate whether continuation of dialysis was truly in the patient's best interests, because the risk of exsanguination and immediate death outweighed the benefits of the treatment. The patient's inability to assent to treatment created an inappropriate harm-benefit ratio. As physicians, we are taught to first do no harm. The principle played an important role from the physicians' perspective in supporting the decision to withdraw dialysis as a treatment option.

\section{Conclusion}

Our case provides an example of the complex ethical issues health care practitioners may encounter when life-sustaining treatment is required in a patient with a major psychiatric illness.

In 2005, Klein and colleagues ${ }^{9}$ described that:

Experience with dialysis patients suffering from major psychiatric disorders is limited and chronic dialysis mandates a basal level of patient cooperation. In most cases, the guardian opts for treatment while the patient refuses. Forceful subjection of the patient to dialysis is an alternative but hardly a viable one.

\section{References}

1. Health Care Consent Act. SO 1996, c 2, Schedule A. Available: www.e-laws.gov.on.ca/html/statutes/english/elaws_statutes_96h02 _e.htm (accessed 2014 May 13).

2. Starson v. Swayze, 2003 SCC 32, [2003] 1 SCR 722. Available: http://scc-csc.lexum.com/scc-csc/scc-csc/en/item/2064/index.do (accessed 2014 May 13).

3. Cuthbertson v. Rasouli, 2013 SCC 53, paras 1-122. Available: http://scc-csc.lexum.com/decisia-scc-csc/scc-csc/scc-csc/en/item /13290/index.do (accessed 2014 May 13).

4. Rights and responsibilities: mental health and the law. Toronto (ON): Ministry of Health and Long-Term Care; 2001. Available: www.ontla.on.ca/library/repository/mon/1000/10293918.pdf (accessed 2014 May 13).

5. Evans KG. Consent: a guide for Canadian physicians. 4th ed. Ottawa (ON): Canadian Medical Protective Association; 2006. Available: https://oplfrpd5.cmpa-acpm.ca/en/handbooks/-/asset _publisher/TayXf91AzWR2/content/consent-a-guide-for-canadian -physicians (accessed 2014 May 13).

6. Consent to medical treatment [policy]. Toronto (ON): College of Physicians and Surgeons of Ontario; 2006. Available: www.cpso .on.ca/policies/policies/default.aspx?ID=1544 (accessed 2014 May 13).

7. Jin (next friend of) v. Calgary Health Region, 2007 ABQB 593, para 36. Available: www.albertacourts.ab.ca/jdb_new/public/qb /2003-NewTemplate/qb/Civil/2007/2007abqb0593.pdf (accessed 2014 May 13).

8. Golubchuk v. Salvation Army Grace General Hospital et al, 2008 MBQB 50. Available: www.canlii.org/en/mb/mbqb/doc/2008 $12008 \mathrm{mbqb} 50 / 2008 \mathrm{mbqb} 50 . \mathrm{html}$ ?searchUrlHash=AAAAAQAJR 29sdWJjaHVrAAAAAAE (accessed 2014 May 13).

9. Klein O, Korzets Z, Berheim J. Is a major psychiatric illness a contraindication to chronic dialysis? Nephrol Dial Transplant 2005;20:2608-10.

Affiliations: Division of Nephrology (Kadri), Windsor Regional Hospital, Windsor, Ont.; Division of Physical Medicine and Rehabilitation (Blackmer), Department of Medicine, University of Ottawa, Ottawa, Ont.; Ethics, Professionalism and International Affairs (Blackmer), Canadian Medical Association, Ottawa, Ont.; Department of Medicine (Ibrahim), Windsor Regional Hospital, Windsor, Ont.

Contributors: Albert Kadri and Muhieldean Ibrahim drafted the manuscript, and Jeff Blackmer contributed to the sections on case law and medical ethics surrounding the case. All of the authors contributed substantially to revising the manuscript, approved the final version submitted for publication and agreed to act as guarantors of the work. 